\title{
Clinical Profile of Patients Presenting with Breast Cancer in Nepal
}

\author{
Acharya SC, ${ }^{1}$ Jha AK, ${ }^{2}$ Manandhar $\mathrm{T}^{1}$
}

${ }^{1}$ Department of Radiotherapy and Oncology

National Academy of Medical Sciences, Bir Hospital

Kathmandu, Nepal

${ }^{2}$ Department of Radiation Oncology

B.P. Koirala Memorial Cancer Hospital

Bharatpur, Chitwan, Nepal

\section{Corresponding Author}

Sandhya Chapagain Acharya

Department of Radiotherapy and Oncology,

National Academy of Medical Sciences, Bir Hospital Kathmandu, Nepal

Email: sandhyachap@gmail.com

Citation

Acharya SC, Jha AK, Manandhar T. Clinical Profile of Patients Presenting with Breast Cancer in Nepal. Kathmandu Univ Med J 2012;39(3):3-7.

\section{ABSTRACT \\ Background}

Breast cancer is the second most common cancer in women in Nepal. Even though the evaluation and treatment of patients is done as per western guidelines, there are considerable variations in risk factors, presenting stage and prognostic factors such as receptor status.

\section{Objective}

To evaluate the clinical profile of patients presenting with breast cancer in Nepal.

\section{Method}

The study was conducted at Department of Radiotherapy and Oncology, Bir Hospital and Department of Radiation Oncology, BP Koirala Memorial Cancer Hospital, Bharatpur from 16th July 2007 to 15 th June 2008 for a period of one year and 114 patients were enrolled. Detailed history, clinical examination and necessary investigations performed. Histological features including receptor status were recorded. Tumor Node Metastasis (TNM) staging system was as per American Joint Committee on Cancer (AJCC), fifth edition. Data was collected in preformed case report form and was managed using SPSS version 13.

\section{Results}

The incidence was high (34.2\%) among perimenopausal women age ranging from 41 to 50 . The majority of women presented with lump (98.2\%) and others with pain (21.9\%), nipple retraction (16.7\%), ulceration $(7.9 \%)$, discharge $(7 \%)$, or symptoms of metastasis (6.1\%). Regarding receptor status, the majority (64.0\%) were Estrogen receptor (ER) and Progesterone receptor (PR) negative with 21.9 percent. ER+PR+, Younger women were more likely to be both ER and PR negative. Where available, Her2 immunohistochemistry showed that $45.0 \%$ of post menopausal women were Her-2 neative, compared to $64.0 \%$ of premenopausal women. Incidence of Triple negative disease was $41.3 \%$. The most common stage at presentation was stage III (26.3\%).

\section{Conclusion}

Majority of patients were perimenopausal, presenting with locally advanced disease (Stage III and Stage II) and with average tumor size two to five $\mathrm{cm}$ and were hormonal receptor negative. These findings are similar to other South Asian population but is inverse than profile reported in Western populations.

\section{KEY WORDS}

Breast Cancer, Estrogen Recepter (ER), Progesterone Recepter (PR), Human Epidermal Growth Factor Receptor - 2 (Her-2/neu) 


\section{INTRODUCTION}

Breast cancer is one of the common and leading causes of cancer related death in females and account for $29 \%$ of all cancers diagnosed each year worldwide. ${ }^{1}$ This disease accounts for $32 \%$ of all female cancers and is responsible for $19 \%$ of cancer related mortality in women worldwide. ${ }^{1}$ From the hospital based cancer registry of Nepal, which contains pooled data from seven major hospitals where cancer is diagnosed and treated, there were a total of 2910 cancer patients in the year 2009, 211 of these were breasts cancers, which represent $7.2 \%$ of all malignancies, and is the second most commonly diagnosed cancer in Nepal. ${ }^{2,3}$ In developed countries, the majority of breast cancers diagnosis is following screening. In developing countries, patients have limited access to screening, or any effective awareness programs and consequently advanced disease. Treatment of breast cancer is multidisciplinary, for early stage disease surgery plays a crucial role followed by radiation therapy and/or chemotherapy depending on tumor size, nodal status, age of patient and histological sub-type. For advanced disease systemic therapy with loco regional treatment is considered. This study aims to evaluate the clinical profile of patients presenting with breast cancer in Nepal.

\section{METHODS}

A observational, cross sectional study was conducted from $16^{\text {th }}$ July 2007 to $15^{\text {th }}$ June 2008 at the Department of Radiotherapy and Oncology, Bir Hospital, Kathmandu and Department of Radiation Oncology, BP Koirala Memorial Cancer Hospital, Bharatpur, Nepal. One hundred and fourteen patients of newly diagnosed cases of histopathologically confirmed breast cancer attending the Radiation oncology outpatient department were consecutively enrolled in the study, and informed consent was taken. Patients with recurrent or previously treated breast cancer, inconclusive diagnosis and who declined consent were not included in the study. Detailed history, clinical examination and necessary investigations performed. Histological features including receptor status were recorded. Patients were staged as per TNM staging fifth edition. Data were collected in preformed Case Report Form and data was processed with Statistical package for social science (SPSS) version 13. Since this was a study of clinical profile only, statistical tests for comparison were not applicable.

\section{RESULTS}

The largest age group represented was 41 to 50 years. There were 111 females (97.4\%) and three males (2.6\%). Among 111 females, 53.5\% were premenopausal whereas $46.5 \%$ were post- menopausal. The majority of women (98.2\%) presented with self detected mass, associated with pain in $25(21.9 \%)$, nine women $(7.9 \%)$ presented with ulceration, eight (7.0\%) had a nipple discharge, 19 (16.7\%) showed nipple retraction whereas seven (6.1\%) presented with symptoms of distant metastasis.

Past history of fibrocystic disease or biopsy for benign condition was present in 12 cases (10.5\%). In hormonal contraception was used only by eight cases (7.0\%). The average age of menarche was $14 \pm 1$ year in 61 cases (53.5\%). History of breast-feeding was present in 96 cases $(84.2 \%)$ and 52 cases $(45.6 \%)$ had their first childbirth before the age of 25 years. Most of the cases (102, 89.5\%) were married or parous, and only 12 cases (10.5\%) were nulliparous. Regarding the distribution of tumor site, 73 cases $(64.0 \%)$ had the tumor in the upper outer quadrant, followed by 15 cases (13.2\%) in central area, 11 cases (9.8\%) in the upper inner quadrant, 10 (8.8\%) in the lower outer quadrant and two cases (1.8\%) in the lower inner quadrant. Just over half the tumors were left sided (58 cases, 50.9\%), whereas 53 cases (46.5\%) were right sided and three cases (2.6\%) had bilateral disease at the time of presentation

Tumor size of two to five $\mathrm{cm}$ during presentation was observed in majority of cases $(74,64.9 \%)$ followed by tumor size of more than five $\mathrm{cm}$ in 34 cases $(29.8 \%)$ whereas tumor size less than two $\mathrm{cm}$ was seen only in six cases $(5.3 \%)$.

Considering nodal status, 42 cases (36.8\%) had a clinically palpable axillary node at presentation, all of which were sampled, and histopathological analysis of 79 cases (69.2\%) turned out to be positive for tumor cells.

Histological analysis showed that the majority of cases 54 (47.4\%) were Grade II tumors, followed by Grade I with 33 cases (28.9\%), whereas only 23 cases (20.2\%) had high grade III tumor. When Stage distribution was done, 53 cases (46.5\%) were Stage III, 48 (42.1\%) were Stage II, six (5.4\%) were Stage I and seven cases (6.1\%) were Stage IV. While analyzing receptor status, 73 cases (64.0\%) have both ER-/ PR-, 25 cases (21.9\%) were both $\mathrm{ER}+\mathrm{PR}+, 11$ cases (9.6\%) were ER-/PR+ and five cases (4.4\%) were ER+/PR-. All of the three cases $(100 \%)$ of metastatic breast cancer $(\mathrm{MBC})$ were ER-/PR+ (Fig. 1).

Her-2/neu was associated with liver (visceral) metastasis. Among 114 cases, Her-2/neu receptor analysis was done only in 46 cases (table 1 ). Her-2/neu positivity was inversely correlated with age. Her-2/neu was also analyzed in seven

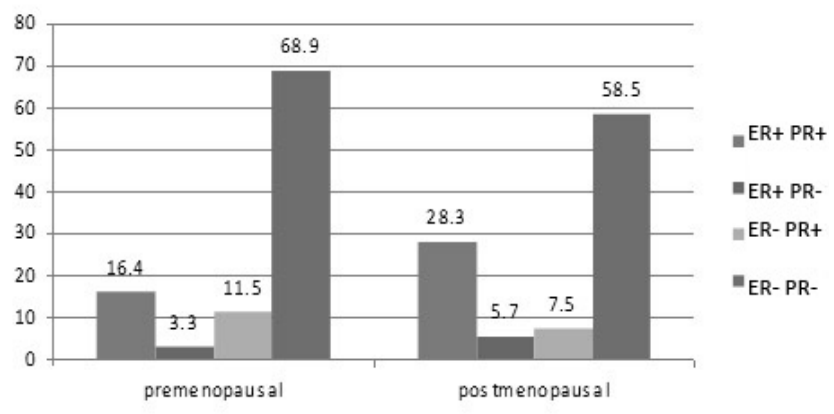

Figure 1. Distribution of receptor status according to menopausal status. 
Table 1. Correlation of Her-2/neu receptor with menopausal status.

\begin{tabular}{lllll|} 
HER-2/neu Status & \multicolumn{2}{c}{ Postmenopausal } & \multicolumn{2}{c}{ Premenopausal } \\
& N & $\%$ & N & $\%$ \\
\hline Negative & 9 & $45.0 \%$ & 16 & $64.0 \%$ \\
\hline Positive & 11 & $55.0 \%$ & 9 & $36.0 \%$ \\
\hline Total & 20 & $100.0 \%$ & 25 & $100.0 \%$ \\
\hline
\end{tabular}

cases of metastatic breast cancer (MBC), where four cases with liver metastasis were positive for Her-2/neu and three cases with bone metastasis were negative. Furthermore, only one patient out of three cases of male breast cancer underwent Her-2/neu analysis and was positive.

Most common type of breast cancer was Invasive Ductal Carcinoma Not Otherwise Specified (IDC NOS) with 100 cases $(89.47 \%)$ followed by adenosquamous and lobar carcinoma with four cases (3.51\%). We also encountered papillary, nosimedullary, mucinous, and squamous cell types of breast cancer with much less frequency (1\% each). All the three cases of MBC studied turned out as IDC NOS. Patients were then offered various combinations of adjuvant treatment depending on their staging and preference and very few patients also received neoadjuvant chemotherapy.

\section{DISCUSSION}

With the exception female gender, increasing age is the most consistent and significant risk factor for breast cancer. Personal history and family history of breast cancer, nulliparity or late age at first childbirth, early menarche and late menopause, prior breast biopsy with hyperplasia or atypical hyperplasia, high breast tissue density, radiation exposure at a young age, alcohol consumption, and use of postmenopausal hormone therapy are other risk factors. ${ }^{4}$ The risk of breast cancer increases exponentially up to the age of menopause, and then the rate of increase in the risk slows significantly. ${ }^{5}$ In our study the most frequent age group to have diagnosed breast cancer was between $41 y r s$ to $55 y$ rs of age. Also in this study, $53.5 \%$ of cases were premenopausal and remaining 46.5 percent were postmenopausal. Similarly premenopausal breast cancer comprised of $60 \%$ of all breast cancers in both Nepalese and Japanese women with breast cancer. ${ }^{6}$

In this study, majority of cases were in stage III (53\%), and stage II (48\%). A similar study compared 109 breast cancer patients from Nepal with 108 breast cancer patients treated at Kansai Medical University Otokoyama Hospital Osaka, Japan between 1993 to 1998 and showed that 60 percent of breast cancer patients were in premenopausal period both in Nepalese and Japanese women. ${ }^{6}$ At the time of diagnosis, $50 \%$ of Nepalese breast cancer patients were in stage III and stage IV, while $88 \%$ of Japanese breast cancer patients were in stage I and stage II.

The protective effect of child bearing at younger ages on breast cancer risk is well established along with a nearly linear relationship between relative risk of breast cancer and age at first child birth where the age of first childbirth at age of 20 to 25 having nearly a $50 \%$ reduction in the relative risk of breast cancer compared to nulliparous women. ${ }^{7,8}$ Surprisingly, most of the cases (52\%) in this study had first childbirth at the age less than 25 years. History of breast-feeding was also present in $96 \%$ of patients and only few cases were nulliparous.

$\mathrm{ER}+/ \mathrm{PR}+$ type of breast cancer was the commonest and its occurrence ranged from 61 to $65 \%$ in Western countries whereas in Asian countries ER-/PR- breast cancer is most prevalent. ${ }^{9-11}$ No significant difference was observed in $\mathrm{ER}+$ / PR- breast cancer in Western and Asian countries. Again, variation was again found in ER-/PR+ breast cancers with the incidence of ER-/PR+ breast cancer was 0 to $3.8 \%$ in Western communities but in Asian communities, it ranged from 2.8 to $21.1 \%{ }^{11-13}$ In our study, $73.0 \%$ were ER-/PRfollowed by $21.9 \%$ with ER+/PR+, $9.6 \%$ with ER-/PR+ and $4.4 \%$ with ER+/PR- respectively. These findings are similar to some studies from India. ${ }^{12}$ Few studies also showed ER positivity in $72 \%$ of postmenopausal patients and $57 \%$ of premenopausal patients. ${ }^{14}$

Her-2/neu receptor positivity was analyzed in only 45 females in the study. Among them only $36.0 \%$ of premenopausal women were positive whereas $55 \%$ of postmenopausal women were positive for Her-2/neu receptor. Frequency of Positivity was also seen more with younger age group than with older age. Her-2/neu receptor was also analyzed in seven cases (6.1\%) with metastatic breast cancer. Liver metastasis was seen in four cases (3.5\%), bone metastasis was seen in three cases $(2.6 \%)$ and one case had both $(0.9 \%)$. It was also found that Her-2/neu positivity was associated with the visceral metastasis than boney metastasis which. An immunohistochemical study performed in 319 paraffin embedded blocks of breast cancer reported that, compared with Her-2/neu negative tumors, those with over-expression of this gene metastasized three times more often to the lungs, liver and brain and three times less often to the bone. ${ }^{15}$ The prognostic value of Her$2 /$ neu overexpression may be related not only to increased cell proliferation rate but also to a distinctive pattern of metastasis and the same also occurred in our study with four cases (66.7\%) of metastatic breast cancer had Her-2/ neu overexpression who had Liver metastasis.

This study has three male breast cases comprising $2.9 \%$ of the total. While evaluating, all male breast cancers were IDC NOS and immunoprofile observed was ER negative / PR positive. High levels of estrogen (81\%) and progesterone (74\%) receptors are found in the largest literature review of studies of 1301 male breast cancer patients. ${ }^{16}$

Among the 114 cases, 113 received systemic Chemotherapy (CT) either in the form of Neoadjuvant CT (NACT), Adjuvant CT. Only one case had a very small tumor size of $0.5 \mathrm{~cm}$ (pT1pN0) and thus received only Radiotherapy (RT) as 
Breast Conservation Surgery (BCT/BCS) was done. Patients with invasive breast cancer that are $E R+/ P R+$ should be considered for adjuvant endocrine therapy regardless of age of patient, lymphnode status or whether or not adjuvant chemotherapy is to be administered. Anastrazole (Arimidex), Tamoxifen, Alone or in Combination (ATAC) trial indicated that Her-2 amplification is a marker of relative endocrine resistance independent of type of endocrine therapy. ${ }^{17}$ This trial also demonstrated that Anastrazole is superior to Tamoxifen or the combination of Tamoxifen and Anastrazole in the adjuvant endocrine therapy of the postmenopausal women with hormone receptor positive breast cancer. The most firmly established adjuvant endocrine therapy is Tamoxifen for both premenopausal and postmenopausal women. Various prospective randomized trials demonstrate that the optimal duration of Tamoxifen appears to be five years. ${ }^{17}$ Based on various trials, there are a number of options for receptor positive postmenopausal patients, including aromatase inhibitors Anastrozole or Letrozole for five years, initial Tamoxifen for two to three years followed by Exemestane, or Tamoxifen for five years followed by five years of Letrozole. ${ }^{17-21}$

Evaluation of receptor status in the management of breast cancer has become the standard of care. Even though the need of identifying the receptor status has long been recognized, it's been not more than four years that it is available in our country. Now we routinely request for this immunohistochemistry (IHC) analysis of the receptor status before starting treatment. In our study, majority of cases were ER/PR negative, which are comparable with the results from the study done in India and Thailand. ${ }^{12,22}$ Most of our patient, 73 cases (64.0\%) also did not receive Hormonal Therapy (HT) based on the receptor status evaluation with IHC as they were both ER-/PR-. Only 41 cases $(36.0 \%)$ were either ER/PR positive or ER+ or PR+ and thus were candidates for receiving hormonal therapy, and were prescribed HT depending upon the menopausal status. In postmenopausal age group ER-/PR- were 38 cases (58.5\%). But in patients with both ER+/PR+ (15 cases, $28.3 \%$ ), ER+ (3 case, $5.7 \%$ ) or PR+ (4 cases, $7.5 \%$ ) were scheduled to receive either Tamoxifen for five years, or Aromatase inhibitor for five years, or Tamoxifen for two years followed by three years of Aromatase inhibitor. Further, evaluating the receptor status in premenopausal age group, 42 cases (72.4\%) were both ER-/PR- and thus did not require adjuvant hormonal therapy. Only 10 cases $(17.2 \%)$ were both $\mathrm{ER}+/ \mathrm{PR}+$, two cases $(3.4 \%)$ were only $\mathrm{ER}+$ and four cases (6.9\%) were only $\mathrm{PR}+$, so this group were also started on hormonal therapy using regimen as per the postmenopausal group. ${ }^{17-21}$

One of the most significant recent advances in breast cancer treatment has been the introduction of Trastuzumab into the adjuvant treatment for patients with tumors that have gene amplification of the Her-2/neu gene.23 Various landmark trials like the National Surgical Adjuvant Breast and Bowel Project (NSABP) B-31, Herceptin Adjuvant (HERA)
Trial, Finher study and Breast Cancer International Research Group (BCIRG) evaluated the adjuvant Trastuzumab with chemotherapy for patients with Her-2/neu positive breast cancer showed that risk reduction of recurrence of 52, 46, 58 and 39 percent respectively. ${ }^{24-27} \mathrm{Her}-2 /$ neu is amplified or overexpressed in up to 30 percent of in human breast carcinoma. ${ }^{28}$ Overexpression of this protein is associated with tumor aggressiveness and decreased disease-free survival in node-positive patients, with variable prognostic significance among node-negative patients. Several studies mentioned above have demonstrated that Her-2/neu status may be predictive of response to hormonal therapy, resistance to alkylating agent-based chemotherapy, and response to Taxanes and Anthracyclines. In our study, among 114 cases, only 46 cases had Her-2/neu status available and further 25 cases were negative for the Her-2/neu receptor whereas 21 cases had Her-2/neu overexpression. When this was compared as per menopausal status, among premenopausal group 16 cases (64.0\%) were Her$2 /$ neu negative and only nine cases (36.0\%) had Her-2/ neu overexpression and in postmenopausal group, nine cases $(45.0 \%)$ were negative and 11 cases (55.0\%) had Her-2/neu overexpression. This showed that Her-2/neu overexpression is more frequent with the premenopausal age group rather than postmenopausal. Most of our young cases were ER-/PR- with Her-2/neu positive which shows there is negative correlation between hormone receptors expression and Her-2/neu amplification as in various literatures. ${ }^{29,30}$ This suggest that the younger patients with breast cancer are more aggressive and carries the poorest prognosis.

\section{CONCLUSION}

The study concluded that most of the patient in our setup present with locally advanced disease i.e., Stage III (53\%) and Stage II (48\%), Considering, the receptor status ER-/PRcases were most prevalent as reported by studies in other South Asian population which are inversely related to the prevalence reported in Western populations. ${ }^{11-13,21-23,29,30}$

Based on our study findings, we recommend that:

- Implementation of the simple and effective screening programs for early detection is urgent need in our population.

- Adjuvant hormonal therapy in our setup should be based on the presence of hormone receptors, as assessed by immunohistochemical staining of breast cancer tissue.

- Hormone negative breast cancer over express Her-2/ neu receptor. These breast cancers behave aggressively but respond well to Trastuzumab as well as to Taxanes and Anthracyclines. As ER/PR negative breast cancers were predominant in our population, it is appropriate to evaluate Her-2/neu status with the hormonal status for the optimization of the treatment for every case of breast cancer. 


\section{ACKNOWLEDGEMENT}

The authors would like to thank all from Department of Radiotherapy and Oncology at NAMS, Bir Hospital and

\section{REFERENCES}

1. Box BA, Russell CA. Breast Cancer. In: Dennis A Casciato, editor. Manual of Clinical Oncology. Fifth ed. Philadelphia: Lippincot Williams and Wilkins. 2005. p. $250-253$

2. Annual Report 2005. B.P. Koirala Memorial Cancer Hospital, Bharatpur Nepal.

3. Shrestha HG, Dali S, Sayami G, Osti B, Amatya VJ, Basnet RB. Present cancer scenario and its changing pattern at Tribhuban University Teaching Hospital, Nepal. JNMA. 1997:35;45 - 51

4. Colditz GA. Epidemiology and prevention of breast cancer. Cancer Epidemiol Biomarkers Prev .2005; 14: 768-772.

5. Smigal C, Jemal A, Ward E, Cokkinides V, Smith R, Howe HL, et al. Trends in breast cancer by race and ethnicity: update 2006. CA Cancer J Clin. 2006; 56: 106-130.

6. Singh Y, Sayami P, Sayami G, Nakagawa H, Kooreeda T. Nepalese Breast Cancer in Relation to Reproductive Factors: Comparision between Nepalese and Japanese cases. Anticancer Research. 2002; 22: 319324.

7. MacMahon B, Purde M, Cramer D, Hint E. Association of breast cancer risk with age at first and subsequent births: a study in the population of the Estonian Republic. J Nat/ Cancer Inst. 1982; 69: 1035-1038.

8. MacMahon B. Epidemiology and the causes of breast cancer. Int J Cancer. 2006; 118: 2373-2378.

9. Colditz GA, Rosner BA, Chen WY, Holmes MD, Hankinson SE. Risk factors for breast cancer according to estrogen and progesterone receptor status. J Nat Cancer Inst. 2004; 96(3): 218-28.

10. Chu KC, Anderson WF, Fritz A, Ries LA, Brawley OW. Frequency distributions of breast cancer characteristics classified by estrogen receptor and progesterone receptor status for eight racial/ethnic groups. Cancer. 2001; 92(1): 37-45.

11. Redkar AA, Kabre SS, Mittra I. Estrogen \& progesterone receptors measurement in breast cancer with enzyme-immunoassay \& correlation with other prognostic factors. Indian J Med Res. 1992 Feb; 96: 1-8.

12. Desai SB, Moonim MT, Gill AK, Punia RS, Naresh KN, Chinoy RF. Hormone receptor status of breast cancer in India: a study of 798 tumors. Breast 2000 Oct; 9(5): 267-70.

13. Ratnatunga $\mathrm{N}$, Liyanapathirana LV. Hormone receptor expression and Her/2neu amplification in breast carcinoma in a cohort of Sri Lankans. Ceylon Med J. 2007; 52(4): 133-6.

14. Lower EE, Blau R, Gazder P, Stahl DL. The effect of oestrogen usage on subsequent hormone receptor status of primary breast cancer. Breast cancer research and treatment. 1999; 58(3): 205-210.

15. Kallioniemi OP, Holli $\mathrm{K}$, Visakorpi $\mathrm{T}$, Koivula $\mathrm{T}$, Helin $\mathrm{HH}$, Isola JJ. Association of c-erbB-2 protein over-expression with high rate of cell proliferation, increased risk of visceral metastasis and poor long-term survival in breast cancer. Int J Cancer. 1991; 49:650-5.

16. Giordano SH, Buzdar AU, Hortobagyi GN. Breast cancer in men. Ann Intern Med. 2002; 137(8): 678-87.
Department of Radiation Oncology, BP Koirala Memorial Cancer Hospital, Bharatpur for their support and also to Ms Amita Pradhan for her support in data management.

17. Howell A, Cuzick J, Baum M, Buzdar A, Dowsett M, Forbes JF et al. Results of the ATAC (Arimidex, tamoxifen, alone or in combination) trial after completion of 5 years' adjuvant treatment for breast cancer. Lancet. 2005; 365:60-62.

18. Goss PE, Ingle JN, Martino S, Robert NJ, Muss HB, Piccart MJ et al. A randomized trial of letrozole in postmenopausal women after five years of tamoxifen therapy for early-stage breast cancer. NEJM. 2003; 349:1793-1802.

19. Goss PE, Ingle JN, Alés-Martínez JE, Cheung AM, Chlebowski RT, Wactawski-Wende J, et al. Exemestane for breast-cancer prevention in postmenopausal women. NEJM. 2011 Jun 23; 364(25): 2381-91.

20. Coombes RC, Hall E, Gibson LJ, Paridaens R, Jassem J, Delozier T et al. Intergroup exemestane study. A randomized trial of exemestane after two to three years of tamoxifen therapy in postmenopausal women with primary breast cancer. NEJM. 2004; 350: 1081-1092

21. Breast International Group (BIG) 1-98 Collaborative Group, Thürlimann B, Keshaviah A, Coates AS, Mouridsen H, Mauriac L, Forbes JF et al. A comparison of letrozole and tamoxifen in postmenopausal women with early breast cancer. NEJM. 2005; 353: 2747-2757.

22. Lertsanguansinchai $P$, Chottetanaprasith T, Wannakrairot P. Oestrogen and progesterone status in Thai female breast cancer patients: an analysis of 399 at King Chulalongkorn Memorial Hospital. Journal of the medical Association of Thailand. 2002; 85 Suppl 1: S193-202.

23. Jahanzeb M. Adjuvant trastuzumab therapy for HER2-positive breast cancer. Clin Breast Cancer. 2008; 8(4): 324-33.

24. Romond EH, Perez EA, Bryant J, Suman VJ, Geyer CE Jr, Davidson NE et al. Trastuzumab plus adjuvant chemotherapy for operable HER2positive breast cancer. NEJM. 2005; 353: 1673-1684.

25. Piccart-Gebhart MJ, Procter M, Leyland-Jones B, Goldhirsch A, Untch M, Smith I et al. Trastuzumab after adjuvant chemotherapy in HER2positive breast cancer. NEJM. 2005; 353: 1659-1672.

26. Joensuu H, Kellokumpu-Lehtinen PL, Bono P, Alanko T, Kataja V, Asola R et al. Adjuvant docetaxel or vinorelbine with or without trastuzumab for breast cancer. NEJM. 2006; 354: 809-820.

27. Slamon D, Eiermann W, Robert N, Pienkowski T, Martin M, Press M, et al. Adjuvant trastuzumab in HER2-positive breast cancer. $N$ Engl J Med. 2011 Oct 6; 365(14): 1273-83.

28. Menard S, Valagussa P, Pilotti S, Gianni L, Biganzoli E, Boracchi P et al. Response to cyclophosphamide, methotrexate, and fluorouracil in lymph node-positive breast cancer according to HER2 overexpression and other tumor biologic variables. J Clin Oncol. 2001; 19: 329-33.

29. Dutta V, Chopra GS, Sahai K, Nema SK. Hormone receptors, Her-2/ $\mathrm{Neu}$ and chromosomal aberrations in breast cancer. Medical Journal Armed Force India. 2008; 64: 11-16.

30. Arafah M. Correlation of Hormone Receptors with Her-2 Neu Protein Expression and the Histological Grade in Invasive Breast Cancers in a Cohort of Saudi Arabia. Turk Patoloji Derg. 2012; 28(1): 38-43. 